\title{
Interactions between Catanionic Vesicles and Oppositely Charged Polyelectrolytes-Phase Behavior and Phase Structure
}

\section{Eduardo F. Marques, ${ }^{,+,, \ddagger}$ Oren Regev, $\$$ Ali Khan, ${ }^{\dagger}$ Maria da Graça Miguel, $\neq$ and Bjorn Lindman ${ }^{\dagger}$}

Physical Chemistry 1, Center for Chemistry and Chemical Engineering, P.O. Box 124, Lund University, Lund S-221 00, Sweden; Department of Chemical Engineering,

Ben-Gurion University, P.O. Box 653, 84105 Beer-Sheva, Israel; and Departamento de Química, Universidade de Coimbra, 3049 Coimbra, Portugal

Received March 9, 1999; Revised Manuscript Received J uly 19, 1999

\begin{abstract}
Structural and phase behavior effects resulting from the addition of a polyelectrolyte to a solution of oppositely charged vesicles are investigated in this work. Two cationic polyel ectrolytes derived from hydroxyethylcellulose were used: J R400, a homopolymer, and Quatrisoft LM 200, a polymer modified with alkyl side chains. The vesicles are composed of mixed anionic surfactant (sodium dodecyl sulfate) and cationic surfactant (didodecyldimethylammonium bromide), bearing $29 \mathrm{~mol} \%$ of the cationic amphiphile. The phase behavior for the two mixed polymer-surfactant systems was investigated for polymer concentrations between 0.001 and $3 \mathrm{wt} \%$. Three main regi ons were found in the two-phase maps, upon polymer addition: (i) a bluish solution phase; (ii) a wide region of phase separation, containing a precipitate and a solution; and (iii) a polymer-rich gel regi on, forming upon charge reversal of the system. Cryo-TE M imaging of the solution phase shows the formation of faceted vesicles and disk like aggregates, upon addition of J R400. For the LM200 system, besides the formation of faceted vesicles, clusters of vesicles and other bilayer structures are imaged. In the polymer-rich phase of J R400, membrane fragments, disklike aggregates, and vesicles are also found. These bilayer aggregates are likely to be involved with the polymer in highly connected networks, giving rise to the observed bluish gels. Electrostatic interactions, reinforced by hydrophobic interactions in the case of LM200, are the main driving force for the structural transitions observed.
\end{abstract}

\section{Introduction}

Aqueous polymer-vesicle systems constitute a type of mixed colloidal system which has been under intensive experimental research in the last two decades. The polymers may comprise synthetic polymers or biological macromolecules such as proteins, polysaccharides, and nucleic acids. The mixed biopolymer-liposome systems are good model systems for living cells since these are composed of lipidic membranes which interact structurally and functionally with a variety of biopolymers, from periferal and integral proteins to the macromolecules which form the cell's cytoskeleton and glycocalix.1,2 Insight on vesicle bilayer-polymer interactions at a molecular level has al so attracted theoretical interest. ${ }^{2-4}$ The polymer can act as a liposome stabilizer and controller of membrane permeability in liposomal systems for drug delivery. ${ }^{5}$ Nonadsorbing polymers, such as poly(ethylene)glycol (PEG), can induce aggregation and fusion of vesicles, ${ }^{6-8}$ due to a polymer-induced attractive depletion force between the vesicles.

The polymer can interact directly with the vesicle bilayer by means of (i) hydrophobic interactions (by incorporation of hydrophobic moieties in the polymer chain), ${ }^{9-13}$ (ii) electrostatic interactions in charged systems, 4,12,14,15 or (iii) both hydrophobic and el ectrostatic interactions simultaneously. ${ }^{16}$ Systems containing polycations and negatively charged vesicles are of particular interest, because of their analogy with biological cells. The surface of cells has a net negative

* Author for correspondence. E-mail: eduardo.marques@ fkem1.lu.se or emarques@ci.uc.pt.

† Lund University.

₹ Universidade de Coimbra.

$\S$ Ben-Gurion University. charge and thus interacts strongly with natural polycations, such as proteins at $\mathrm{pH}$ values bel ow isoel ectric points, and synthetic polycations. Extensive work has been done on the structural and functional effects arising from the interaction between various type of proteins and polypeptides and negatively charged liposomes. ${ }^{17-20}$ Different types of phenomena have also been reported in mixed systems of synthetic polycationnegatively charged liposome, comprising changes in the chain melting temperature and permeability of the bilayer, flip-flop of lipid molecules, and disintegration and fusion of liposomes. ${ }^{16,21-23}$

From a phase behavior point of view, the polymervesicle systems may lead to novel and interesting phenomena, such as the formation of gels and networks, $10,11,14,24$ with potential practical applications. Thermal gelation has been observed in systems of hydrophobically modified polymer and nonionic surfactant bilayers and associated with cross-linking of the vesicles by the polymer chains. ${ }^{10}$ The stabilization of double-chained surfactant vesicles by polymers containing terminally placed hydrophobes has also been observed, ${ }^{11,24}$ in some cases leading to transient gels of rheological interest. ${ }^{11}$

In this work, mixtures of a cationic polyel ectrolyte and net negatively charged catanionic vesicles are investigated. The catanionic vesicles are composed by mixed cati onic and anionic surfactants. ${ }^{25}$ Our goals are manifold: (i) to start by characterizing the main features of the phase behavior of the system, which is a multicomponent polymer-surfactant-surfactant system; (ii) to probe the effect of the macromolecule on the structure and stability of vesicles, at low polymer concentration; and (iii) to search for the possibilty of vesicle-polymer 
gel formation, at high polymer concentrations. The polycations used consist of the homopolymer J R400 and the hydrophobically modified polymer LM200. Charged sodium dodecyl sulfate (SDS)-rich vesicles, characterized in a previous work, ${ }^{25}$ display suitable properties for this study. The vesicles are essentially small and unilamellar, form spontaneously in water, and remain as a stable phase with time. In a previous short communication we presented a preliminary account of the features of the phase behavior and the imaging of microstructures for these mixed polymer-vesicle systems. ${ }^{26}$ In the current paper, a more comprehensive investigation of the same issues is reported.

The interactions between polymers and oppositely charged surfactants in general have been comprehensively reviewed. ${ }^{27,28}$ In these types of mixtures, associative phase separation is the ruling phenomenon and it consists either of coacervation or precipitation. Coacervation involves a liquid-liquid phase separation, in which one of the liquids is highly concentrated in both polymer and surfactant and the other is a very dilute solution. In the case of precipitation, the concentrated phase is of solidlike character, with either crystalline or amorphous structure. The phase behavior of the systems J R400-SDS 29,30 and LM 200-SDS ${ }^{31}$ has been thoroughly studied. A cryo-TEM investigation of the sol ution and heterogeneous regions for the J R400-SDS system is also reported. ${ }^{32}$ While the systems investigated in this work bear some analogy with the latter polymer-surfactant systems, they also present some important differences. In this work, (i) polymer is added to a solution of preformed aggregates (vesicles), where the surfactant monomer concentration is low and thus kinetic aspects may play an important role. (ii) The surfactant consists of an anionic surfactant-cationic surfactant mixture at a fixed mixing ratio. (iii) Thus, both polymer-surfactant and surfactant-surfactant systems of opposite charges are simultaneousl y present. To emphasize the fact that the surfactant consists of a catanionic mixture, the current polymer-surfactant systems will be referred to as polymer-catanionic systems.

\section{Experimental Section}

1. Materials. Sodium dodecyl sulfate (SDS) and didodecyldimethylammonium bromide (DDAB), of high purity, were obtained from BDH and Tokyo Kasei, respectively, and used without further purification (Figure 1a). The two cationic polyel ectrolytes used, J R400 (a homopolymer) and Quatrisoft LM200 (a polymer modified with hydrophobic chains), are manufactured by Union Carbide Chemicals and Plastics Company, Inc. Both macromolecules are derivatives of HEC (hydroxyethyl cellulose) in the chloride salt form, and their structures can be seen in Figure 1b. J R400 is an N,N,Ntrimethylammonium derivative with a molecular weight of approximately $500000 .{ }^{33} \mathrm{An}$ aqueous solution of $1 \% \mathrm{w} / \mathrm{w}$ of this polymer bears a charge concentration of $10 \mathrm{~mm} .{ }^{34} \mathrm{LM} 200$ is an $\mathrm{N}, \mathrm{N}$-dimethyl-N-dodecylammonium derivative with a molecular weight of approximately $100000,33,34$ The dodecyl hydrophobic side chain is attached to the polymer backbone through the quaternary ammonium bearing the charge, which makes the structure of the macromolecule resemble that of a cationic surfactant (DoTAC) attached by the headgroup to a HEC backbone. The charge density of LM 200 is lower than that of J R400, with a $1 \% \mathrm{w} / \mathrm{w}$ aqueous solution bearing a charge concentration of about $2 \mathrm{~mm} .{ }^{35}$ The degree of hydrophobic modification is 5.4 hydrophobic chains per 100 sugar residues. The relevant structural parameters for the two polymers are listed in Table 1 (see also Figure 3).

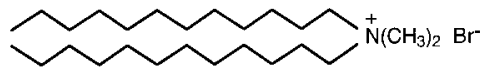

didodecyldimethylammonium bromide (DDAB)

$\sim \mathrm{OSO}_{3}^{-} \mathrm{Na}^{+}$

sodium dodecyl sulphate (SDS)

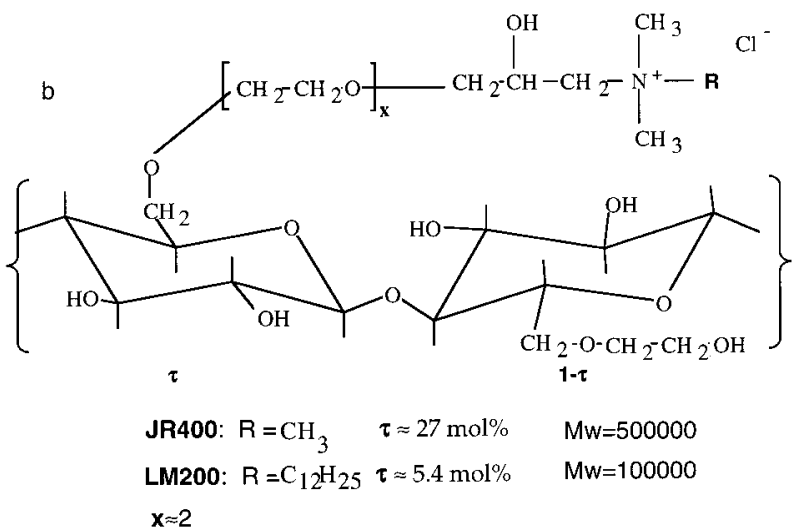

Figure 1. Chemical structure of the molecules used in this work: (a) the surfactants DDAB and SDS and (b) the cationic polymers J R400 (homopolymer) and LM200 (hydrophobically modified).

Table 1. Structural Parameters for the Polymers J R400 and LM200

\begin{tabular}{|c|c|c|c|c|}
\hline polymer & $\begin{array}{c}\text { molecular } \\
\text { weight }\end{array}$ & $\begin{array}{l}\text { mean } \\
\text { contour } \\
\text { length } \\
(\mathrm{nm})\end{array}$ & $\begin{array}{c}\text { charge concen- } \\
\text { tration in a } \\
1 \text { wt\% aqueous } \\
\text { solution (mm) }\end{array}$ & $\begin{array}{l}\text { mean contour } \\
\text { length between } \\
\text { charges }(\mathrm{nm})\end{array}$ \\
\hline $\begin{array}{l}\text { J R400 } \\
\text { LM200 }\end{array}$ & $\begin{array}{l}500000 \\
100000\end{array}$ & $\begin{array}{r}\sim 1000 \\
\sim 200\end{array}$ & $\begin{array}{r}10 \\
2\end{array}$ & $\begin{array}{r}2 \\
10\end{array}$ \\
\hline
\end{tabular}

2. Sample Preparation and Phase Diagram Determination. The polymer-surfactant samples were mixed by weight from a polyelectrolyte solution and a surfactant solution containing catanionic SDS/DDAB vesicles. A stock vesicle solution was prepared with a total surfactant concentration of $\mathrm{C}_{\mathrm{s}}=\mathrm{C}_{\mathrm{SDS}}+\mathrm{C}_{\mathrm{DDAB}}=55 \mathrm{~mm}$ and a DDAB molar fraction in the mixture of $X_{D D A B}=C_{D D A B} /\left(C_{S D S}+C_{D D A B}\right)=0.29$. This stock solution was prepared by volumefrom a SDS micellar solution and a DDAB carefully homogenized dispersion, as described previously. ${ }^{25}$ Proper mixing of the polymer-surfactant solutions was ensured by initial vigorous hand shaking followed by continuous end-over-end shaking for at least $48 \mathrm{~h}$. Samples with higher polymer concentration were heated at $40-50^{\circ} \mathrm{C}$ for a few hours and then centrifuged mildly. In the LM200catanionic system, a significant observation is that equilibration of all monophasic samples with polymer concentration higher than $0.1 \mathrm{wt} \%$ required heating to $40-50^{\circ} \mathrm{C}$. After preparation at room temperature, the viscous solution samples obtained appeared initially hazy and the gel samples showed a mixture of doudy domains and clear gel areas. After heating, all samples became clear and homogeneous and remained so with time, at room temperature. Equilibrated samples in both systems were viewed between crossed polaroids in order to check for birefringence. The presence of crystals and liquid crystals was checked by light microscopy.

3. Cryogenic Transmission Electron Microscopy (CryoTEM). Cryo-TEM was used for structural studies in the solution and gel phases. Vitrified samples were prepared and imaged according to the usual procedure. The sample is placed in the controlled environment vitrification chamber at room temperature, ${ }^{36}$ where relative humidity is kept dose to saturation to prevent water evaporation from the sample. A $5 \mu \mathrm{L}$ drop of the solution is put on a carbon-coated holey film ${ }^{37}$ supported by a TEM copper grid. After gently blotting the drop 


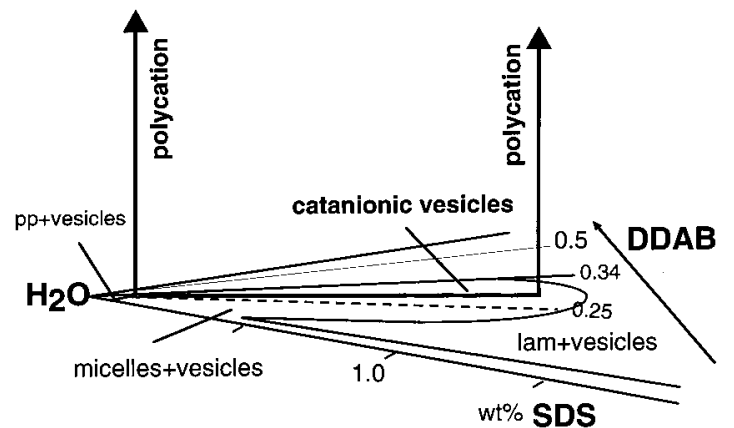

Figure 2. Schematic representation of the approach used for the phase behavi or study of polymer-vesicle systems (see also text).

with filter paper in order to create a thin liquid film over the grid, it is rapidly plunged into liquid ethane at its melting temperature, so that a vitrified film is obtained. The vitrified specimen is then transferred under liquid nitrogen environment by use of a cold stage unit (Model 626, Gatan Inc., Warrendale, PA) into the electron microscope. A Philips CM 120 Bio-twin microscope was used, specially designed for handling cryogenic samples. The lens system gives maximum contrast and sufficient resolution for biological samples (3.4 $\AA$ ). The digital acquisition of images allows the possibility of in situ improvement of the image quality (if appropriately handled) and, importantly, of subsequent image processing.

4. Rheology. Preliminary rheol ogical measurements were carried out for viscous solutions and gels which displayed a bluish translucence in the surfactant-J R400 system. A controlled stress rheometer Carri-Med CSL 100, of cone-plate geometry, equipped with automatic gap setting, was used. The experiments were performed as frequency sweeps in the range $0.01-10 \mathrm{~Hz}$ at a constant strain. Torque sweeps were previously run for all samples to ensure the choice of a strain value in the linear viscoelastic regime. The storage modulus, G', gives a measure of the elastic properties of the material, associated with its ability to store energy. The loss modulus, G", gives a measure of the viscous properties associated with dissipation of work done on the material.

\section{Results}

1. Approach Taken and Phase Behavior Overview. The determination of the phase behavior was carried out by gradual addition of cationic polyel ectrolyte to the surfactant solution containing previously assembled catanionic SDS-rich vesicles. The procedure is schematically depicted in Figure 2. The total surfactant concentration in the polymer-vesicle mixture, $\mathrm{C}_{\mathrm{S}}$, was varied in the range of $5-50 \mathrm{~mm}$, corresponding to a dilution path between 1.0 and 0.1 wt \% SDS spanning the vesicle-only solution region (Figure 2 ). The composition of $X_{D D A B}=0.29$ lies midway in the range of $X_{D D A B}$ for the vesicle region. ${ }^{25}$ The difficulty in presenting the phase behavior for these multicomponent polymersurfactant systems is evident from Figure 2. The surfactant sol ution al ready is a four-component system for which the triangular phase diagram is an approximate representation (strictly accurate only for the location of single-phase regions). ${ }^{38}$ The presence of an additional component, the cationic polyel ectrolyte, which can chemically interact with one of the surfactants, the anionic SDS, brings about further complexity to the dimensionality of the system, in terms of the phase rule. Thus a generic phase behavior will be presented in phase maps-log-log plots of polymer weight percent vs total surfactant concentration, in millimolal-where the single phase and multiphase regions experimentally found are indicated (Figures 4 and 5).

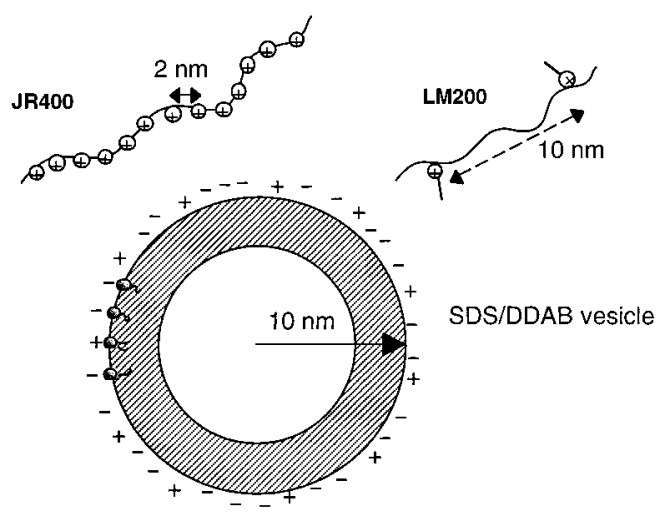

Figure 3. Schematic representation of the interacting polymer and vesicle structures; length scales involved in the system are also shown. The mean contour length between charges (not the mean linear repeat distance) is given in nanometers for both polymers. The net negatively charged SDS/DDAB vesicle is also shown with a radius of $10 \mathrm{~nm}$, drawn approximately in scale with polymer length scales.

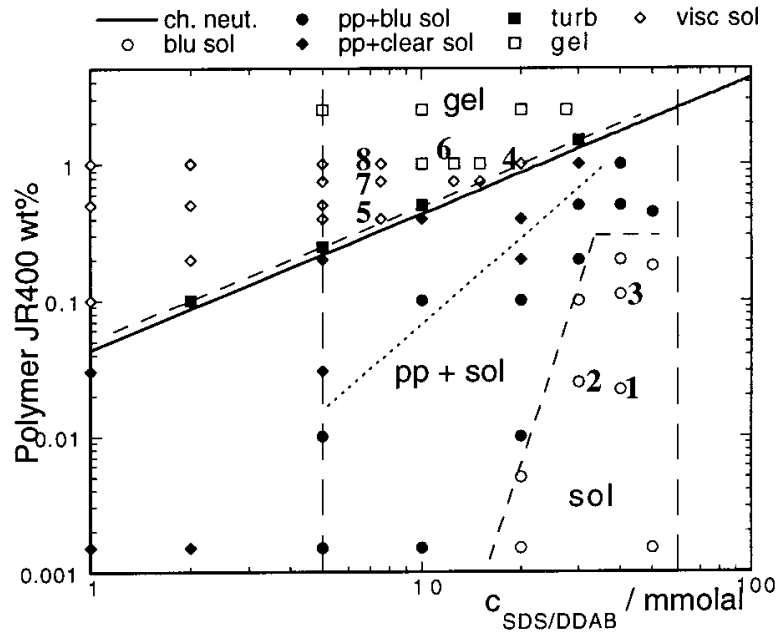

Figure 4. Phase map for the aqueous J R400-SDS/DDAB system at $25^{\circ} \mathrm{C}$. Catanionic mixture with a fixed composition of $\mathrm{X}_{\mathrm{DDAB}}=0.29$. Numbers indicate corresponding samples in Table 2. Vertical lines mark the range of surfactant concentration for the vesicle solution. The line denoted by ch. neutr. indicates charge neutrality. Phase notations: sol, solution; blu sol, bluish solution; pp, precipitate; clear sol, clear solution; turb, two-phase sample (coacervate); visc sol, viscous solutions.

The polymer-free vesicular solutions have been characterized in detail previously. ${ }^{25}$ They contain a large concentration of relatively small and polydisperse unilamellar vesicles, with diameters in the range of 20$70 \mathrm{~nm}$ and an average size of ca. $30 \mathrm{~nm}$. The vesicles have a smooth, spherical shape. A very small fraction of giant vesicular aggregates $(1-40 \mu \mathrm{m})$, mainly unilamellar vesicles in the range of $0.8-3 \mu \mathrm{m}$, is also present. ${ }^{25}$ Dilution within the vesicle region $\left(C_{s}=5-50\right.$ $\mathrm{mm}$ ) does not induce any detectable changes in shape and average size of the vesicles. The maximal volume fraction enclosed by the vesicles is of ca. 0.10 , at $C_{s}=$ $58 \mathrm{~mm}$, as probed by water self-diffusion. ${ }^{25}$ The existence region of the vesicles is limited. For $\mathrm{C}_{\mathrm{s}}>58 \mathrm{~mm}$ and $\mathrm{C}_{\mathrm{s}}<5 \mathrm{~mm}$, heterogeneous regions occur. In particular, for $\mathrm{C}_{\mathrm{s}}<5 \mathrm{~mm}$, a precipitate appears in equilibrium with the bluish vesicular solution, thus setting a lower stability limit for the single solution region of vesicles. Nevertheless, the phase behavior of the polymer-surfactant mixture has also been investigated between 1 and $5 \mathrm{~mm}$ (cf. Figures 4 and 5), since 


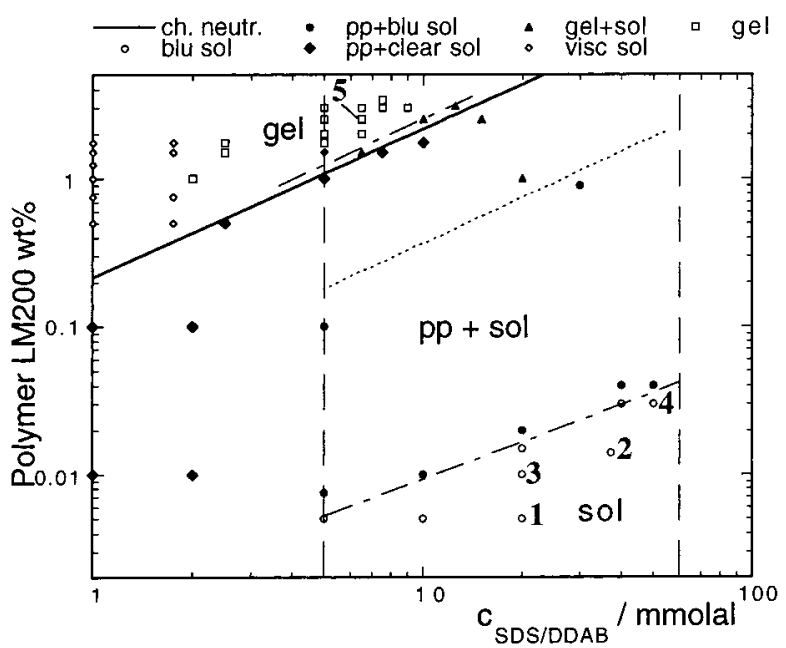

Figure 5. Phase map for the aqueous LM200-SDS/DDAB system at $25^{\circ} \mathrm{C}$. The catani onic mixture has a fixed composition of $X_{D D A B}=0.29$. Numbers indicate the location of corresponding samples in Table 3. Notations are the same as in Figure 4.

we wanted to examine the influence of the polyel ectroIyte on the precipitate-vesicle equilibrium.

A schematic view of the colloidal length scales involved in the current polymer-surfactant systems is presented in Figure 3. A vesicle with a typical diameter of $20 \mathrm{~nm}$ is shown in scale with the mean charge-tocharge contour lengths of both polyelectrolytes (Table 1): $2 \mathrm{~nm}$ for J R 400 and $10 \mathrm{~nm}$ for LM200. The LM 200 molecule has on average 20 hydrophobic side chains. This means that the average contour length of one LM200 chain is on the order of $200 \mathrm{~nm}$. J R400 has on average 500 charges per chain, implying a mean contour length for the molecule of about $1 \mu \mathrm{m}$.

Since electrostatic interactions are at play in the mixed systems investigated here, the description of the phase behavior can be made in terms of the molar fraction of polymer charge in the mixture, defined as $f_{p_{+}}=C_{p_{+}} /\left(C_{p_{+}}+C_{s_{-}}\right)$, where $C_{p_{+}}$is the molal concentration of polymer charge and $\mathrm{C}_{\mathrm{S}_{-}}$is the molal concentration of net surfactant charge, i.e., $\mathrm{C}_{S_{-}}=\mathrm{C}_{\mathrm{SDS}}-$ $C_{D D A B}$. The full straight lines drawn in the phase maps (Figures 4 and 5) correspond to charge neutrality in the system; i.e., $\mathrm{f}_{\mathrm{p}+}=0.50$. Thus, bel ow the line the system is net negatively charged-owing to the surfactant-and above it, it is net positively charged-owing to the polymer.

It can be seen in Figures 4 and 5 that upon polymer addition to the surfactant solution, three main regions are found: (i) a solution single phase, which can only take up a relatively small amount of polymer (surfactant-rich phase); (b) a wide region of phase separation, containing a precipitate and a solution, present up to a slight excess of polymer charge in the system; and (c) a gel region after redissolution of the precipitate (polymerrich phase). The phase separation observed in our systems is, as expected, of the associative type: a concentrated phase in both polymer and surfactant-a precipitate-is in equilibrium with a solution dilute with respect to both species.

(a) J R 400-Catanionic System. As shown in Figure 4 a single phase region consisting of a bluish turbid solution is still found upon polymer addition until a certain value of $f_{p+}$ is attained. Above this value, henceforth termed $f_{p p}$, a two-phase region appears consisting of a white solidlike precipitate and a liquid supernatant. A phase boundary is thus defined, referred to as the lower precipitation boundary, LP-boundary. It is evident from the profile of the LP-boundary in Figure 4 that $\mathrm{f}_{\mathrm{pp}}$ rises sharply with surfactant concentration-for example, at $\mathrm{C}_{\mathrm{s}}=20 \mathrm{~mm}, \mathrm{f}_{\mathrm{pp}} \approx 0.007$ while at $\mathrm{C}_{\mathrm{s}}=40 \mathrm{~mm}, \mathrm{f}_{\mathrm{pp}} \approx 0.15$ (the maximum value obtained).

A significant observation is that the macroscopic appearance of the supernatant liquid changes with the concentration of added polymer, within the two-phase region. At lower polymer concentrations, the supernatant is a bluish turbid solution, which suggests that large aggregates (either surfactant-only or mixed polymer-surfactant) are present. Closer to the charge neutralization line the liquid is clear and of low viscosity, appearing like a very dilute solution. A dashed line inside the two-phase region has been tentatively drawn, separating the two types of samples.

Addition of polymer at a concentration slightly higher than that for neutralization results in the formation of another single phase region. Hence an upper boundary for the two-phase region is found, designated here as the UP-boundary-upper precipitation boundary. The line is parallel and close to the charge neutralization line, thus denoting that the "redissolution" of the polymer-surfactant precipitate occurs at a constant molar fraction of polymer charge, found to be $f_{p_{+}} \approx 0.54$. The two-phase regi on bears an asymmetry with respect to the neutralization line: a small excess of polymer charge (4 mol \%) is needed to solubilize the precipitate, whereas a much larger excess of surfactant charge (a minimum of $35 \mathrm{~mol} \%$ ) is required to bring about the same effect. The trend is typical in polymer-surfactant mixtures of opposite charge, as exemplified by the J R400-SDS 29 and LM200-SDS ${ }^{39}$ mixtures. Interestingly, within a small range of polymer concentrations above the charge neutralization line, the samples consist of a turbid, bluish, relatively viscous liquid (filled squares in Figure 4). After some days, these dispersions slowly phase-separate into two liquids, implying that a narrow coacervation (liquid-liquid two-phase) region is present here. The upper liquid is clear and low viscous, whereas the bottom is a viscous turbid solution.

In the polymer-rich single phase, the samples display slightly different macroscopic behavior, depending on their composition (Figure 4). For lower surfactant concentrations, the samples consist of highly viscous solutions, which flow slowly under gravity. At higher polymer or surfactant content the samples are best described as gels, flowing very slowly under gravity. A striking feature of these solution/gel samples is their bluish translucence, giving indication that they contain aggregates or colloidal domains large enough to scatter visible light. Another significant observation is that for $\mathrm{C}_{\mathrm{s}}=1-5 \mathrm{~mm}$, where the surfactant-surfactant system shows a precipitate, addition of polymer charge beyond neutralization removes the precipitate and induces the formation of highly viscous solutions. The sol ubilization of the catanionic precipitate in presence of polymer reveals the strong character of the polymer-surfactant association.

(b) LM200-Catanionic System. The phase behavior for the LM200-surfactant system (Figure 5) presents some similarities to that of the J R400-surfactant system. A sequence of solution region-precipitation-"redissolution" is also observed upon polymer 
Table 2. Cryo-TEM Observations in the System J R 400-SDS/DDAB ( $\left.\mathrm{X}_{\text {DDAB }}=0.29\right)$

\begin{tabular}{|c|c|c|c|c|c|c|c|c|c|}
\hline \multirow[b]{2}{*}{ J R400 (wt\%) } & \multirow[b]{2}{*}{$\mathrm{Cs}_{\mathrm{s}}^{\mathrm{a}}(\mathrm{mm})$} & \multirow[b]{2}{*}{$f_{P+}{ }^{b}$} & \multirow[b]{2}{*}{ sample no. } & \multicolumn{6}{|c|}{ observations $^{c}$} \\
\hline & & & & phase & SUVs & MLVs & disks & faceted vesicles & membrane fragments \\
\hline 0 & 40 & 0 & 0 & S & घ & $\square$ & & & \\
\hline 0.022 & 40 & 0.013 & 1 & S & 口 & D & & & \\
\hline 0.025 & 30 & 0.019 & 2 & $\mathrm{~S}$ & $\square$ & & D & D & D \\
\hline 0.11 & 40 & 0.059 & 3 & S & $\square$ & & D & D & $\square$ \\
\hline 1 & 20 & 0.54 & 4 & VS & D & & ש & & \\
\hline 0.4 & 7.5 & 0.55 & 5 & VS & D & & D & & च \\
\hline 1 & 12.5 & 0.66 & 6 & G & $\square$ & & 口 & & $\square$ \\
\hline 0.75 & 7.5 & 0.70 & 7 & G & $\square$ & & 口 & & \\
\hline 1 & 7.5 & 0.76 & 8 & G & घ & $\square$ & $\square$ & $\square$ & $\square$ \\
\hline
\end{tabular}

a Total surfactant concentration. ${ }^{b}$ Mole fraction of polymer charge. ${ }^{c} \mathbf{\square}$, dominant; $\mathbf{\square}$, fair; $\square$, sparse; S, bluish solution; G, gel; VS, viscous, turbid solution.

Table 3. Summary of Cryo-TEM Observations for the System LM200-SDS/DDAB (XDAB $=0.29$ )

\begin{tabular}{|c|c|c|c|c|c|c|c|c|c|}
\hline \multirow[b]{2}{*}{ LM200 (wt \%) } & \multirow[b]{2}{*}{$\mathrm{Cs}_{\mathrm{s}}^{\mathrm{a}}(\mathrm{mm})$} & \multirow[b]{2}{*}{$f_{\mathrm{P}+}{ }^{b}$} & \multirow[b]{2}{*}{ sample no. } & \multicolumn{6}{|c|}{ observations ${ }^{c}$} \\
\hline & & & & phase & SUVs & MLVs & disks & faceted vesicles & membrane or clusters \\
\hline 0 & 40 & 0 & 0 & $\mathrm{~S}$ & 口 & $\square$ & & & \\
\hline 0.005 & 20 & 0.0012 & 1 & $\mathrm{~S}$ & $\overline{\mathbf{n}}$ & & & $\square$ & \\
\hline 0.014 & 37.3 & 0.0017 & 2 & $\mathrm{~S}$ & 口 & & D & D & \\
\hline 0.01 & 20 & 0.0023 & 3 & $\mathrm{~S}$ & $\overline{\mathbf{a}}$ & $\square$ & & $\square$ & $\mathbf{D}(\mathrm{c})$ \\
\hline 0.03 & 50 & 0.0028 & 4 & $\mathrm{~S}$ & $\overline{\mathbf{D}}$ & & $\square$ & $\overline{\mathbf{a}}$ & $\mathbf{D}$ (c) \\
\hline 2 & 6.5 & 0.59 & 5 & G & $\square$ & & $\overline{\mathbf{a}}$ & & $\mathbf{\square}(\mathrm{m})$ \\
\hline
\end{tabular}

addition. However, some distinctive features between the two polymer - catanionic systems are apparent. The LP-boundary in the LM200 system can be reasonably fitted to a straight line in a linear-linear plot (which shows as a slightly curved line in the log-log map in Figure 5), thus lying parallel to the charge neutralization line. In other words, this means that $f_{p p}$ is practically independent of surfactant concentration $\left(\mathrm{f}_{\mathrm{pp}} \approx\right.$ $0.004 \pm 0.001$ ), in contrast with the J R400 system.

Similar to the J R400 system, a line can be drawn inside the two-phase region (dashed line in Figure 5), separating samples where the supernatant is bluish and slightly viscous (lower area) from those where it is clear and not viscous (upper area). The preci pitate is of white solidlike nature. For a concentration of polymer slightly above the equivalent charge concentration, phaseseparated samples show a viscous gel in equilibrium with a clear liquid. No coacervation region is observed, in contrast to the J R400 system. The UP-boundary occurs at a constant $f_{P+}$ value of about 0.57 . Since this value is noticeably similar to that observed in the J R400 system, it can be concluded that electrostatics are the driving force for phase separation in this region.

It was also observed that (i) gel formation occurs at values of excess polymer charge comparatively lower than those for the J R400 system and also at much lower surfactant concentration (cf. sample at 1 wt \% and $C_{s}$ $=2 \mathrm{mM}$ in Figure 5); (ii) the gels are much more viscous than those observed for J R400 at comparable polymer charge and $C_{S}$ (the gels do not flow under gravity). At $\mathrm{C}_{\mathrm{S}}<5 \mathrm{~mm}$ and at excess polymer charge, the polymer induces solubilization of the SDS/DDAB precipitate, similar to the J R400 system. Moreover, gels can be found at much lower surfactant concentrations, for example at $\mathrm{C}_{\mathrm{s}}=2-3 \mathrm{~mm}$ (Figure 5).

2. Overview of Microstructural Investigation. The aggregation microstructure in the bluish solution phase and in the polymer-rich phase observed in the polymer-catanionic systems was investigated by direct imaging with the cryo-TEM method. For the surfactantrich solution phase, the goal was to probe the structural effect of the polyelectrolyte on the surfactant vesicle bilayer, which ultimately leads to phase separation with the formation of a solidlike precipitate. For the polymerrich phase, it was of interest to investigate the presence of vesicular or other type of surfactant aggregates responsible for the gellike behavior. The observations made are summarized in Tables 2 and 3, in which the different aggregate structures detected and their relative abundance are presented. The location of the investigated samples in the phase maps in Figures 4 and 5 is given by the numbers. While at macroscopic scale each sample displays a single isotropic phase, at a microscopic level there is in general a polydispersity of self-assembled structures, not only in size for a particular geometry but, significantly, in terms of a variety of coexisting aggregate structures. However, in most cases, it is possible to identify the dominant type of aggregate form and its characteristic size. So, upon polymer addition there is typically a progressive evolution from a given state of aggregation to another, in general accompanied by the replacement of the dominant structure. Since the polymer is oppositely charged to the surfactant bilayer, it is natural to consider electrostatics as the main driving force for the observed structural changes, and we adopt this view in the description that follows. As will be shown, other factors like the molecular weight and the hydrophobic modification in the case of LM200 also affect the observed sequence of structures.

3. Microstructure in the Surfactant-Rich Phase. A polymer-free vesicular solution at $C_{S}=40 \mathrm{~mm}$ (sample 0, Table 2) was imaged as a referencestateand the results confirm those previously presented. ${ }^{25} \mathrm{Es}$ sentially small unilamellar vesides in the range 20$70 \mathrm{~nm}$ are observed by cryo-TEM, as can be seen in Figure 6A. Also apparent in the figure is the spherical shape of the vesicles and the smooth, integral appearance of the bilayer. A small amount of Iarge vesicular structures (mainly of $0.8-3 \mu \mathrm{m}$ size) are also present in the vesicle solutions, as detected by light microscopy (not shown here).

(a) J R400-Catanionic System. When J R400 is added at a concentration higher than 0.001 wt \% to 


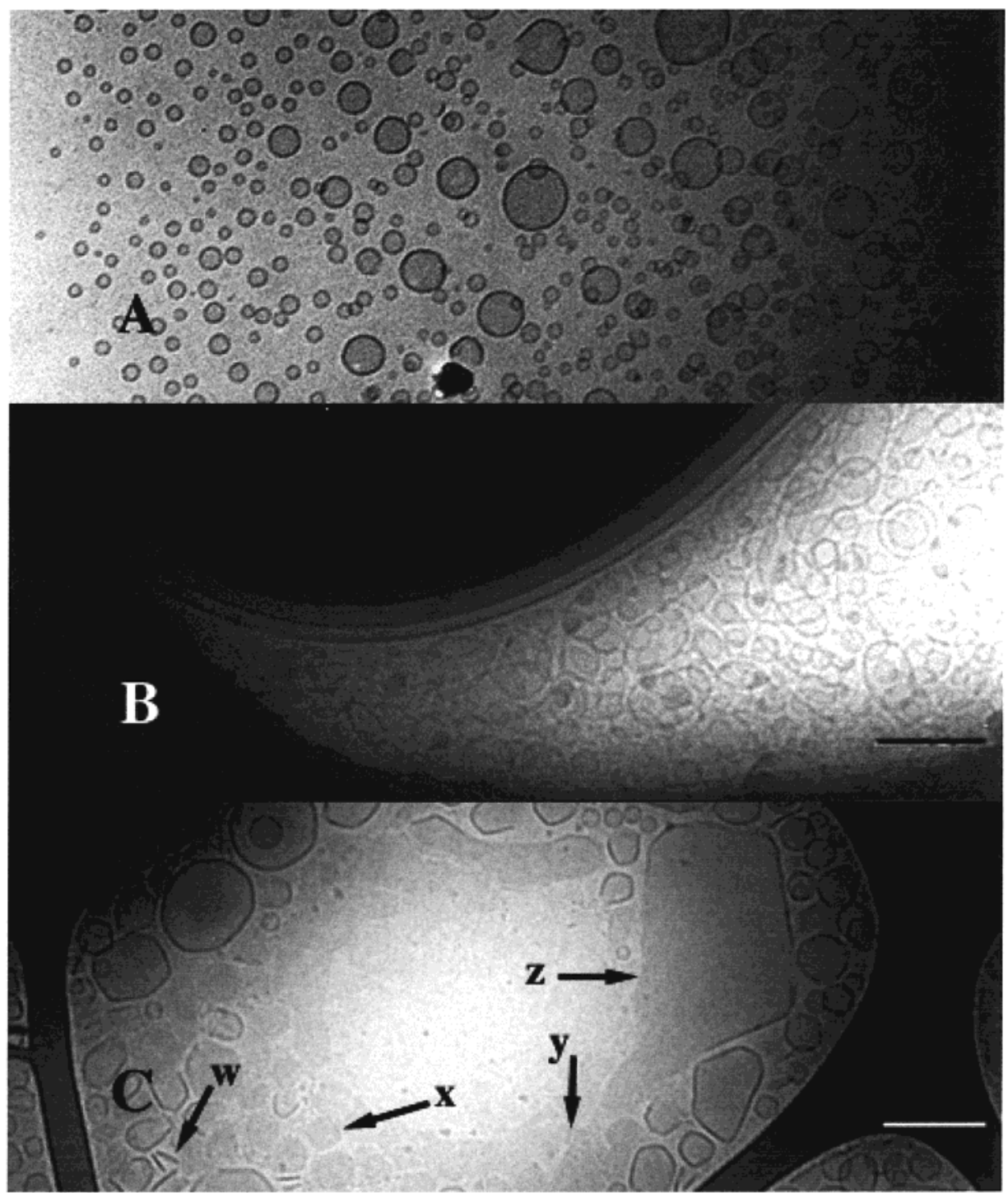

Figure 6. Cryo-TEM micrographs for (A) Mixed SDS/DDAB vesicles (polymer-free solution) at $25{ }^{\circ} \mathrm{C}$ and $\mathrm{X}_{\mathrm{DDAB}}=0.3, \mathrm{C}_{\mathrm{S}}=40$ $\mathrm{mm}$; $(B, C)$ the solution region in the J R400-SDS/DDAB system at $25^{\circ} \mathrm{C}$, (B) 0.022 wt \% J R400, $\mathrm{C}_{\mathrm{s}}=40 \mathrm{~mm}$ (sample 1 , Table 2), SUVs and MLVs and (C) 0.11 wt \% J R 400, $C_{s}=40 \mathrm{~mm}$ (sample 3, Table 2), disks and faceted vesicles. Disks in a face-on (x), or edge-on $(\mathrm{w})$ orientation and bilayers fragments-face-on $(\mathrm{y})$ and partially edge-on $(\mathrm{y})$-and opened vesicles (z). Dominant structures are underlined. Bar $=100 \mathrm{~nm}$.

solutions with $\mathrm{C}_{\mathrm{s}}>20 \mathrm{~mm}$, a bluish, turbid solution phase persists, until a certain value of $\mathrm{f}_{\mathrm{p}+}$ is attained (cf. Figure 4). Addition of a polymer amount corresponding to the lowest value of $\mathrm{f}_{\mathrm{P}}$. investigated, at $\mathrm{C}_{\mathrm{S}}=40$ $\mathrm{mm}$ (sample 1, Table 2) did not result in significant structural change and SUVs remain the dominant structure. Yet, a higher fraction of multilamellar vesides (MLVs), in comparison to the polymer-free solution, is clearly observed. These MLVs can be seen in Figure 6B, where particularly striking is the large number of concentric bilayers observed. This is in contrast to the polymer-free solution where only bilamellar vesicles are detected and in low concentration.

As $f_{p+}$ further increases, toward the vicinity of the precipitation boundary (samples 2 and 3), a dramatic change is seen to occur: faceted vesicles and disklike aggregates now become the dominant structure. A micrograph of sample 3, representative of these changes, is shown in Figure 6C. The effect of the polyelectrolyte on the veside structure, at a value of $\mathrm{f}_{\mathrm{p}_{+}}=0.059$, is evident. Smooth-shaped spherical vesicles are practically absent and they are replaced with faceted, poly- hedron-like vesicles. Some of these vesicles are ruptured, i.e. they show membrane discontinuities (z). In addition to these structures, aggregates of disklike shape (x) are clearly seen in Figure 6C. Both edge-on (w) and face-on (x) projections of the disks with respect to the electron beam are visible. Some irregularly shaped bilayer fragments ( $y$ ) are seen as well. The black contour line on some of these fragments ( $\mathrm{z}$ ) indicates that they are partially viewed in an edge-on orientation, a situation which reflects the fact that the membrane sheet is a flexible surface. We note that disklike micelles have been previously imaged also in the SDS-DDAB system, ${ }^{21}$ in the absence of polymer but for lower values of $\mathrm{X}_{\mathrm{DDAB}}(0.13-0.25)$ than those present in the current samples (0.29).

From sample 2 to 3, the molar fraction of polymer charge is increased 3-fold, but the changes are not very significant. Large faceted vesicles and membrane fragments occur more sparsely in sample 3 than in 2; moreover, sample 3 has a large dominance of disks and faceted vesicles of small size. This may imply that prior to phase separation small and "stiff" bilayer aggregates 


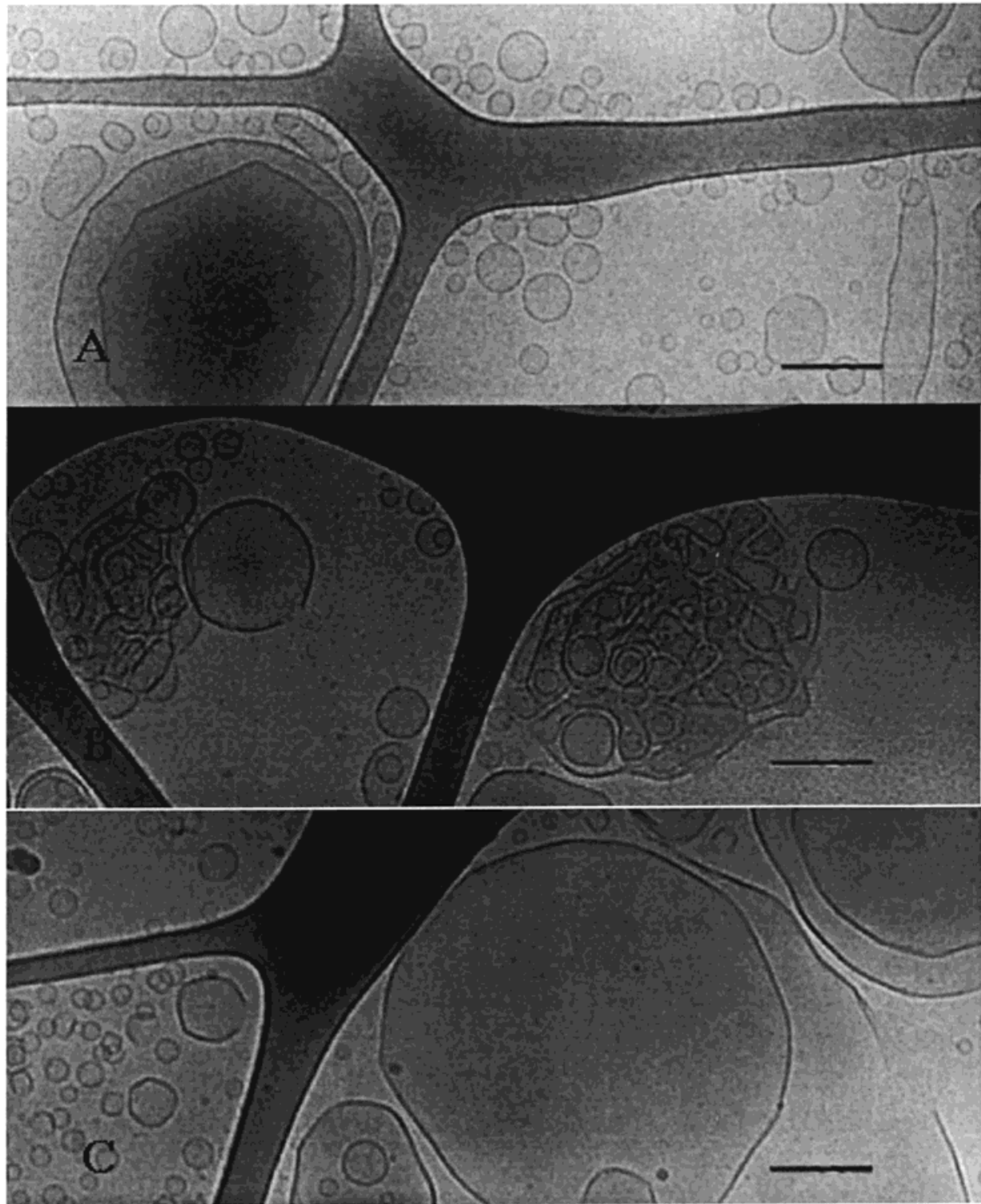

Figure 7. Cryo-TEM micrographs of the solution region in the LM $200-S D S / D D A B$ system at $25^{\circ} \mathrm{C}:$ (A) 0.005 wt $\%$ LM $200, C_{S}$ $=20 \mathrm{~mm}$ (sample 1, Table 3), SUVs and faceted vesicles; (B) $0.01 \mathrm{wt} \%$ LM200, $\mathrm{C}_{\mathrm{S}}=20 \mathrm{~mm}$ (sample 3, Table 3), vesicle clusters, SUVs, faceted vesicles; (C) 0.03 wt \% LM200, Cs $=50 \mathrm{~mm}$ (sample 4, Table 3), ruptured, faceted vesicles, large membrane patches, SUVs. Dominant structures are underlined. Bar $=100 \mathrm{~nm}$.

(disks) are more favored than larger and relatively more flexible ones (membranes). The evolution of aggregate shape in the system, upon polymer addition, may be summed up with the following sequence: SUVs $\rightarrow$ coexistence of SUVs and MLVs $\rightarrow$ faceted vesicles $\rightarrow$ coexistence of disks and faceted vesicles $\rightarrow$ precipitate formation.

(b) LM200-Catanionic System. Addition of LM 200 to the vesicle solution induces structural effects on the vesicle bilayer comparable to those observed with J R400 (Table 3). In fact, as the polymer concentration increases (and, concomitantly, charge neutralization in the system increases), there is a gradual formation of faceted vesicles and disklike aggregates. Moreover, the variety of coexisting aggregate forms increases. At a value of $f_{p+}$ as a low as 0.0012 (sample 1, Table 3), faceted vesicles can already be observed (Figure 7A). From a closer inspection of the micrographs, one can also see that close to the edges of the grid holes (i.e., along the walls of the polymer support film) there is an agglomeration of small vesides, many of which overlap each other. Larger vesicles are seen at the center of the sample film. This is contrary to what is expected. It is well known that from center to edge in the vitrified film there is usually a gradient of aggregate sizes (larger objects toward the edge) - a consequence of the meniscus shape of the liquid film that spans the grid hole. ${ }^{40}$ The observation then strongly suggests that the small vesicles at the edge are somehow interconnected, forming clusters of large size and molecular weight (as compared to the larger vesicles). The effect can be understood if one realizes that the interaction of LM 200 with the vesicles can involve molecular contact. The hydrophobic side chains, bearing the charge, can anchor in the oppositely charged vesicle bilayer, opening the possibility of vesicle cross-linking (often termed bridging as well). Since the mean contour length between the hydrophobes, $10 \mathrm{~nm}$, is on the order of the diameter of the small vesicles, $20-30 \mathrm{~nm}$ (Figure 3 ), it is reasonable to picture that even one LM200 molecule can make cross-links between several small vesicles. We are unable to see the polymer chain itself in the TEM 
micrographs since its diameter is below the resolution of our imaging technique. ${ }^{41}$

When the concentration of polymer is doubled for the same surfactant concentration (sample 3, Table 3), the cross-linking effect becomes even more evident. Clusters of relatively large size containing many bilayer aggregates are observed (Figure 7B), suggesting that the constituent aggregates are strongly interconnected. It is possible to establish the presence of quasispherical small vesicles inside the clusters, but mainly highly deformed polyhedron-like aggregates and membranes fragments are observed. F or a sample in close vicinity to the LP-boundary (sample 4, Table 3), a large number of ruptured vesicular structures together with clusters of small vesides are seen (Figure 7C).

The occurrence of the interconnected vesicles and dense clusters in Figure $7 A-C$ is thus a novel feature of the LM200-surfactant system, as compared to the J R400 system. Also, from the comparison between Tables 2 and 3, it seems that the formation of disk aggregates prior to phase separation is more favored in the J R400 system. For the L M200 system the aggregate evolution toward the LP-boundary is in the direction of faceted vesicles (common feature) and vesicle clusters (novel feature). These differences are likely to stem mainly from the presence of the hydrophobes in the backbone of the LM200 polymer.

4. Microstructure in the Polymer-Rich Phase. (a) J R400-Catanionic System. Samples lying in the polymer-rich phase of this system are highly viscous and therefore pose difficulties in the preparation of thin films in the TEM grids. Nevertheless, it was possible to successfully obtain their imaging with cryo-TEM. Similar factors to those governing structure in the surfactant-rich solution phase region seem to be present here, where now a small excess of polymer charge exists. Immediately above the UP-boundary (close to charge neutralization), the turbid and viscous samples show nonclosed bilayer structures as their dominant aggregation form. Disklike aggregates and large membrane fragments are observed, respectively, for samples 4 and 5 in Table 2. In Figure 8A, a micrograph of sample 5 is shown, where large bilayer fragments can be seen. At higher polymer concentration, in sample 7 (F igure 8B), disklike structures become the dominating structure. Upon further addition of polymer (Figure 8C) essentially vesicles of small size, $20-30 \mathrm{~nm}$ in diameter, mostly intact, can be seen. Again the vesicle wall is in most cases polygon-like. The smaller number density of the vesicles, as compared with Figure 6A, reflects the lower surfactant concentration for this sample. It is striking to observe that at this high polymer concentration, above the neutralization line, the preci pitate disappears and gel-like homogeneous samples are found, where the vesicular structure is reformed. In Figure 8D, mostly disklike structures are observed. They can be seen both in the face-on orientation, creating an almost "fuzzy" background, and in the edge-on orientation. In addition, it is remarkable to note that the vesicular structures display a nonspherical, almost elliptical shape. In this sample, contrary to the surfactant-rich solution samples, faceted objects are practically absent and the vesicles are mostly intact.

At constant total surfactant concentration, one can then sum up the effect of increasing concentration of polymer (samples 5, 7, and 8 corresponding to parts A, $B$, and C, of Figure 8, respectively). As polymer is added,
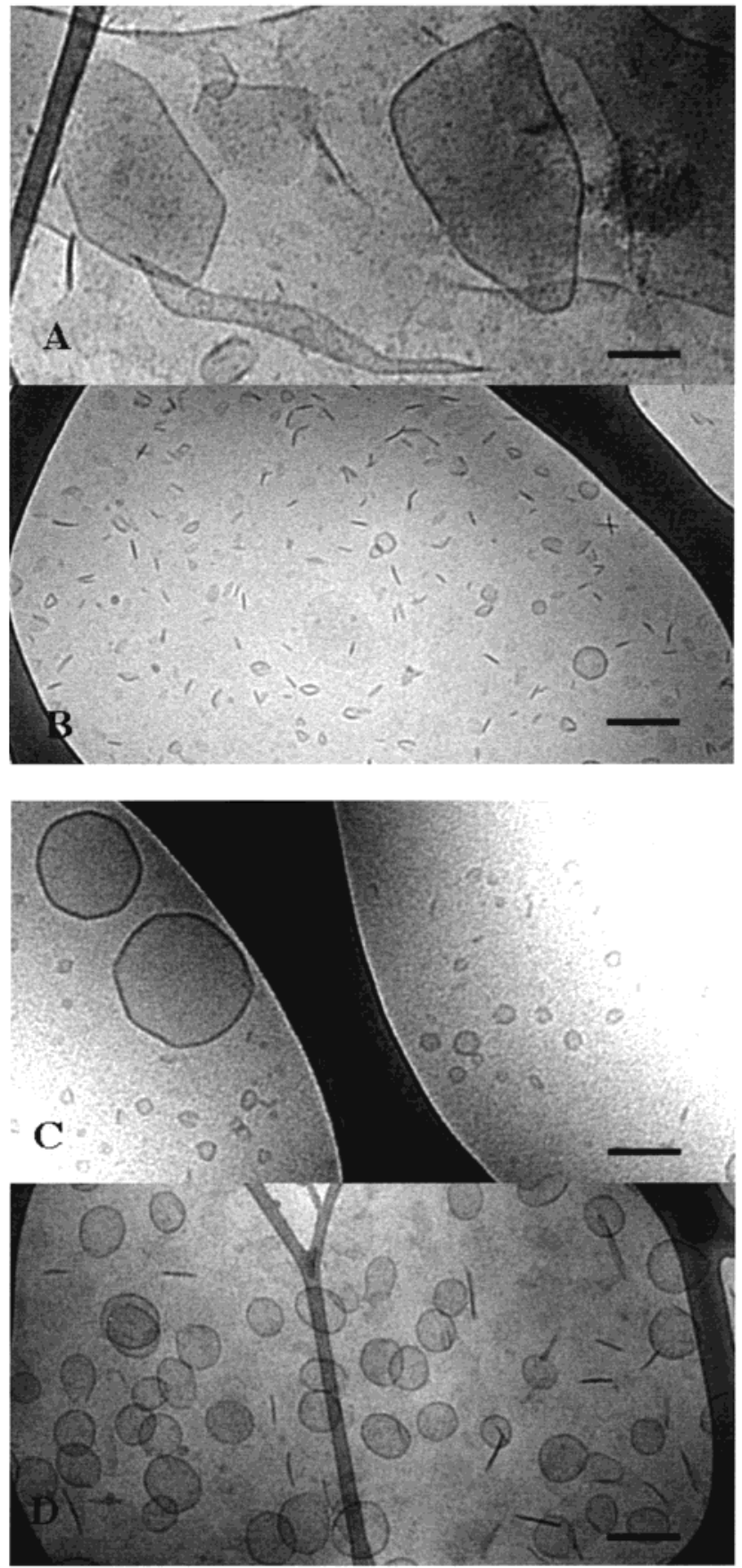

Figure 8. Cryo-TEM micrographs of the viscous solutions and gels in the J R400-SDS/DDAB system at $25^{\circ} \mathrm{C}$ : (A) 0.4 wt \% J $R 400, C_{S}=7.5 \mathrm{~mm}$ (sample 5, Table 2), membrane fragments; (B) 0.75 wt \% J R400, $C_{s}=7.5 \mathrm{~mm}$ (sample 7, Table 2), disks and SUVs; (C) 1.0 wt \% J R400, $C_{s}=7.5 \mathrm{~mm}$ (sample 8, Table 1), SUVs, faceted vesicles, disks; (D) 1.0 wt \% J R400, $C_{s}=20$ mm (sample 4, Table 2), disks and SUVs. Dominant structures are underlined. $\mathrm{Bar}=1 \overline{100 \mathrm{~nm}}$.

a transition in the prevailing structure from large membrane fragments to disklike aggregates and then to SUVs is observed, suggesting an increase in the mean curvature of the aggregate as the excess of polymer charge increases. Also, the change seems to be accompanied by an increase of structural polydispersity. The trends are thus basically opposite to those observed in the sol ution phase as the LP-boundary is approached at fixed surfactant concentration (samples 0,1 , and 3). A consistent structural evolution is also seen in the gel region when the polymer concentration is kept constant 
a

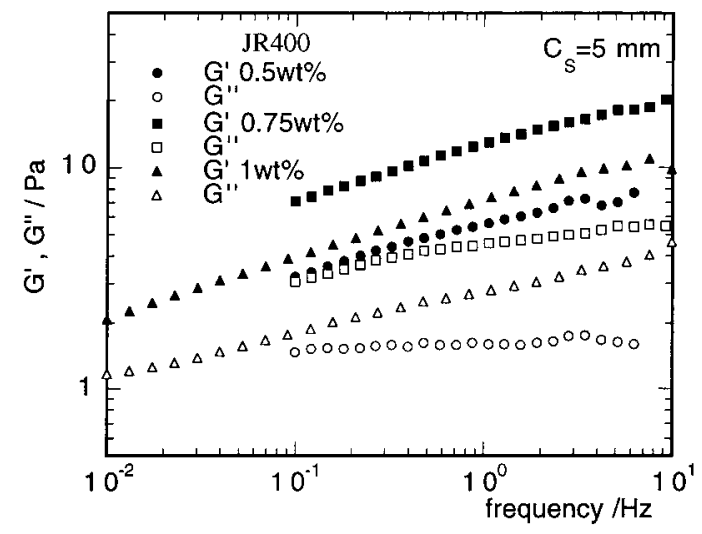

b

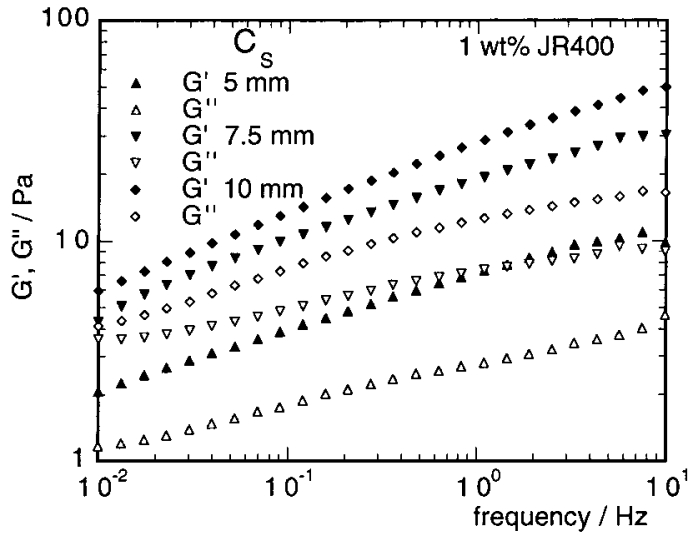

Figure 9. The storage modulus ( $\mathrm{G}^{\prime}$ ) and the loss modulus ( $\left.\mathrm{G}^{\prime \prime}\right)$ vs oscillation frequency for samples in the J R400-SDS/DDAB systems at $25^{\circ} \mathrm{C}$ : (a) at constant total surfactant concentration, $\mathrm{C}_{\mathrm{s}}=5 \mathrm{~mm}$, and increasing polymer concentration and (b) at constant polymer concentration, 1 wt \%, and increasing surfactant concentration, $\mathrm{C}_{\mathrm{s}}$.

and the surfactant concentration increases toward phase separation (samples 8, 6, and 4). Essentially, SUVs are replaced with disklike aggregates as the prevailing structure on going from part $C$ to $D$ of $F$ igure 8.

Rheological Measurements. In order to gain further insight on the properties of the polymer-rich samples imaged by microscopy, prel iminary oscillatory measurements were made. Plots of the rheological parameters $\mathrm{G}^{\prime}$ and $\mathrm{G}^{\prime \prime}$, the shear storage and the shear loss modulus, respectively, vs the oscillation frequency are shown in Figure 9a,b. In Figure 9a, the surfactant concentration was kept constant at $5 \mathrm{~mm}$ and the polymer content increased from 0.5 to 1 wt\%. Ocular inspection of the samples shows that they flow under gravity. It can be seen in Figure 9a that, within the studied frequency range, for all polymer concentrations both moduli show a strong frequency dependence (except for $G^{\prime \prime}$ at 0.5 wt \%) and $G^{\prime}$ values are al ways higher than $G^{\prime \prime}$, indicating that the samples have a weak gellike viscoelastic character. The magnitude of $\mathrm{G}^{\prime}$ and $\mathrm{G}^{\prime \prime}$ is rather low for all samples and at any frequency the highest values occur at 0.75 wt \% polymer. The network appears to be destabilized when the polymer concentration is increased from 0.75 to 1 wt \%. In Figure 9b, the polymer concentration was kept constant at 1 wt $\%$ and the surfactant concentration was increased from 5 to $10 \mathrm{~mm}$. At $\mathrm{C}_{\mathrm{S}}=5$ and $7.5 \mathrm{~mm}$ the samples flow under gravity, whereas at $10 \mathrm{~mm}$ the sample flows very slowly, behaving to the naked eye like a low-viscosity gel. The magnitude of both $G^{\prime}$ and G" increases with surfactant concentration, as can be seen in Figure 9b, and the same trend applies for the slope of log G' vs log frequency, which has a value of 0.34 for $10 \mathrm{~mm}$ as compared to 0.26 for $5 \mathrm{~mm}$. Moreover, at high frequencies the value of $G^{\prime}$ is clearly higher than $G^{\prime \prime}$ for all concentrations, but as the frequency decreases toward the lowest value, $\mathrm{G}^{\prime}$ and $\mathrm{G}^{\prime \prime}$ approach each other for 7.5 and $10 \mathrm{~mm}$, whereas for $5 \mathrm{~mm}$ the difference between them remains practically constant.

This limited rheological study shows that the samples have a gel-like viscoelastic behavior that is dependent on both polymer and surfactant concentration in a complex way. It is possible that the trends observed are correlated with changes in the global microstructure (dominant aggregate shape and aggregate diversity) of the gels both as the polymer concentration increases at fixed $\mathrm{C}_{\mathrm{S}}$ or as $\mathrm{C}_{\mathrm{S}}$ increases at fixed polymer concentration (Table 2). Further characterization of the rheological behavior of the samples in this polymer-rich single phase region is clearly needed and is being currently done, in order to clarify those trends and relate them to the direct structural imaging.

(b) LM200-Catanionic System. Due to the even higher viscosity of the gel samples observed for this system, as compared to the previous one, it was not possi ble to make a detailed imaging study for this area. However, we note that sample 5 (Table 3) showed the presence of disks and membrane fragments, albeit in much lower concentration than in the J R400 samples. This suggests that other types of structures, probably of much larger size than that accessible by cryo-TEM (5-1000 nm), might be present. For example, when observed on a light microscope the same sample showed the presence of clusters of spherical particles, most likely consisting of vesicles (not shown). The vesicles are almost entirely in the range of $10 \mu \mathrm{m}$, no multilamellar structures are seen, and tubular structures also occur. All these individual structures occur in cluster domains of roughly $50 \mu \mathrm{m}^{2}$ of area in the focus plane, apparently highly interconnected. The domains are most likely to be responsible not only for the viscosity of the gels but also for the intensely bluish translucence displayed. The viscous solutions with $\mathrm{C}_{\mathrm{S}}=1-2 \mathrm{~mm}$ show identical type of aggregates when viewed on the light microscope (not shown).

5. Comparison between Polyelectrolyte-Catanionic and Polyelectrolyte-Anionic Systems. Some qual itative comparisons between the phase behavior of the investigated systems and that of the previously reported J R400-SDS ${ }^{42-44}$ and LM200-SDS 31,39 systems are relevant here. The polymer-catanionic systems have some different features: (i) the surfactant consists of a mixture of amphiphiles with an excess amount of the anionic one; (ii) the surfactant is initially aggregated into large structures-vesicles-bearing a net negative charge; and (iii) the concentration of monomeric surfactant is assumed to be low; i.e., $\mathrm{C}_{\text {monomer }} \ll \mathrm{cmc}$ (neat anionic surfactant).

A common feature for all the mixtures is the occurrence of an extensive region of phase separation of the associative type, as shown in the phase map in Figure 10. The polymer charge is plotted vs the surfactant charge, since (i) the polyelectrolytes have different charge density and (ii) for a given surfactant concentration, there is a net charge concentration in the catanionic system which is lower than that in the micellar 


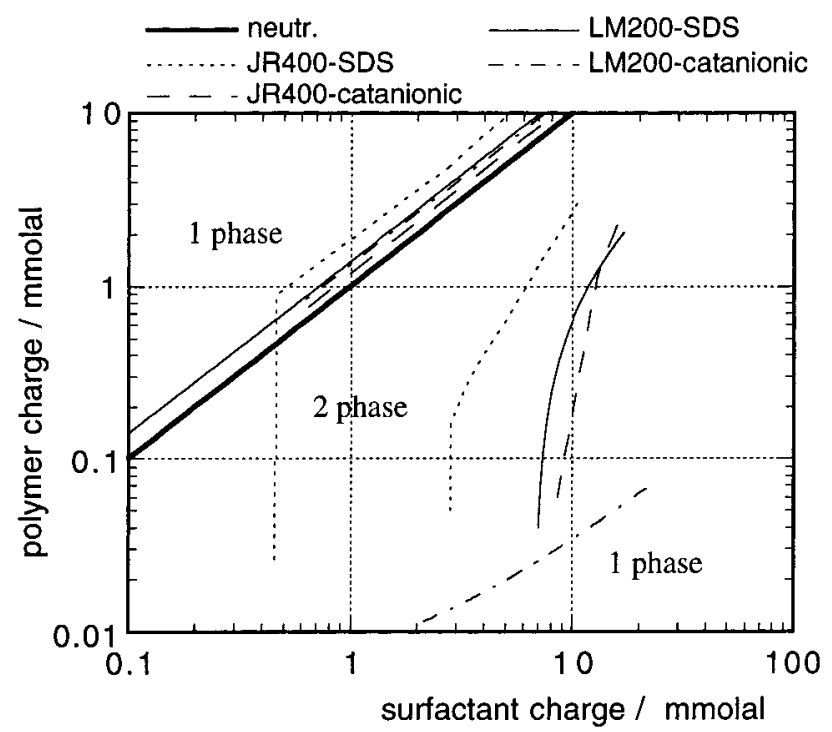

Figure 10. Comparative phase map for the mixed polyelectrolyte-surfactant systems. Lines at lower surfactant charge are coacervation/precipitation boundaries; lines at higher surfactant charge are redissolution boundaries. F or any given system, the region between the two boundaries is a two-phase region. The catanionic system is composed by SDS-DDAB at fixed surfactant mixing ratio of $X_{D D A B}=0.29$. Values for J R400-SDS lines are taken from the work of Goddard et al. ${ }^{43}$ (Figure 5); for LM200-SDS lines are from the work by Guillemet et al. ${ }^{31}$ (Figure 5).

system. Boundaries separating one and two-phase regions are shown. The boundaries for the J R400-SDS system were calculated on the basis of the phase diagrams presented by Goddard et al. ${ }^{43}$ F or the L M $200-$ SDS system we repl ot the values from Guillemet et al. ${ }^{31}$ The concentrated phase in the two-phase region consists of a precipitate in the J R400-SDS system. ${ }^{43}$ In the LM200-SDS system, a coacervate is formed, characterized as a gel-like liquid containing a high degree of polymer cross-linking due to the formation of mixed hydrophobe-SDS micelles. ${ }^{31}$ For these polymer-SDS systems the phase behavior is usually described from the point of view of surfactant addition to polymer solution. Thus the boundary at lower surfactant charge concentration is termed a coacervation or precipitation boundary; that at higher surfactant charge is referred to as a redissolution boundary. ${ }^{28}$ Henceforth we will adopt these designations.

Coacervation/Precipitation. A common trend is observed for the polyelectrolyte-surfactant systems in Figure 10. The coacervation/precipitation boundary occurs close to the charge neutrality line and is parallel to it for all systems (for the J R400-SDS system, this is the case only for $\mathrm{C}_{\mathrm{P}+}>1 \mathrm{~mm}$, according to Goddard et al. $\left.{ }^{43}\right)$. This implies that phase separation takes place when a fixed polymer -surfactant charge stoi chi ometry is attained in the system; thus el ectrostatics are the driving force for the effect. The approximate $f_{p+}$ values for phase separation are similar: 0.54 for J R400catanionic; 0.66 for J R400-SDS; 0.58 for LM 200-SDS; 0.57 for LM 200-catanionic. F or the LM200-SDS system, it has been suggested that the polymer - surfactant complex can be viewed as a single component of variable composition (thus, of varying solubility). ${ }^{28}$ When comparing the LM200-SDS and LM200-catanionic systems, it is observed that the presence of DDAB in the latter has no significant effect on the "Iocation" of the phase boundary. This observation is in contrast to the effect of salt addition to the LM200-SDS mixture. ${ }^{31}$ In the presence of $10 \mathrm{mM} \mathrm{NaCl}$, phase separation is enhanced; i.e., the coacervation line is shifted to lower SDS concentration. The effect has been considered to result from a decreased solubility of the polymersurfactant complex at enhanced ionic strength. ${ }^{31}$ The effect of DDAB addition is obviously very different from a simple electrolyte effect. First, the concentration of $\mathrm{NaBr}$ in the catanionic system-resulting from the formation of the neutral $\mathrm{DDA}^{+} \mathrm{DS}^{-}$pair-is relatively low, at the total surfactant concentration where phase separation takes place. Moreover, the amphiphilic salt DDAB can associate hydrophobically with the anionic surfactant and the polymer, contributing to the net charge stoichiometry required for phase separation in the system.

Redissolution. A general observation in Figure 10 is that the two-phase area for all systems is more stable upon excess surfactant chargethan upon excess polymer charge. The redissolution boundary of the J R400catanionic system is shifted to larger surfactant charge as compared to the J R400-SDS system. It is known that a polyelectrolyte derives its solubility in water from the large entropy of mixing associated with the dissociation of its counterions. Addition of a high enough amount of salt decreases this gain in counterion entropy and may suppress the solubility of the polyelectrolyte. We note that in the catanionic system, at the higher total surfactant concentrations investigated, the concentration of $\mathrm{NaBr}$ resulting from SDS-DDAB neutralization may be high enough to induce such type of salting out effect on polyel ectrolyte solubility.

For the LM200 systems, other mechanisms for redissolution are present, since the polymer interacts hydrophobically with the surfactant, forming molecularly mixed aggregates. First, it should be noted that the redissolution boundary is a straight line in linear-linear plots of polymer concentration vs surfactant concentration for both the LM200-SDS ${ }^{31}$ and the LM200catanionic systems. The observed linearity means that redissolution occurs at a fixed charge stoichiometry. It is also observed in the LM200-SDS system that, at redissolution, the concentration of free surfactant is roughly equal to the $\mathrm{Cmc}$ of neat SDS. This has been interpreted as an indication that redissolution requires that a large net negative charge is attained and/or that the mixed micellar cross-links between different polymer chains disappear. ${ }^{28}$ This should occur when the surfactant can form micelles alone; i.e., when the free surfactant concentration is close to the cmc. Furthermore, a surfactant-to-hydrophobe ratio (binding ratio) in the mixed micelle equal to $\approx 5$ is found at redissolution. In the presence of $10 \mathrm{mM}$ of $\mathrm{NaCl}$, the $\mathrm{cmc}$ is lowered and a larger binding ratio is needed for redissolution; i.e., higher surfactant binding is needed to compensate for the screening of the charges. When turning to the LM200-catanionic system, an explanation for the observed profile of the redissolution line (F igure 10) can be sought, at least partially, in the same trends as for the LM200-SDS system. (i) First, in the catanionic system the free surfactant concentration is very low ( $\mathrm{C}_{\text {mon }} \ll \mathrm{cm} \mathrm{CsDs}_{\mathrm{S}}$ ). Thus, redissolution may occur at much lower surfactant concentration than in the LM200-SDS system (cf. lower surfactant charge in Figure 10). (ii) The slope of the redissolution boundary is considerably lower in the catanionic system as compared to the anionic system (Figure 5), indicating 
that a much larger surfactant-to-hydrophobe ratio is to be attained for redissolution in the former system. We note that both observations (i) and (ii) are qualitatively similar to those found for the polymer-SDS-10 mM $\mathrm{NaCl}$ system, ${ }^{31}$ but the effects are much more pronounced. Thus, the presence of relative large concentration of $\mathrm{NaBr}$ in the catanionic system cannot simply justify the observations. It is likely that other mechanisms also play a role in redissolution.

\section{Summary}

1. Structural Effects in the Surfactant-Rich Phase. The addition of polyelectrolyte to a solution of oppositely charged vesicles can have large effects in the structure and stability of the vesicles. Without polyel ectrolyte, repulsive double layer forces stabilize the charged vesicles. Screening of the el ectrostatic repulsions by the polyelectrolyte, which can be seen as a giant counterion, may cause a decrease in the colloidal stability of the vesicles, leading to an attractive interaction and thus to flocculation of the aggregates. ${ }^{45,46}$ In the current catanionic vesicles systems, in the absence of polymer, there is a non-negligible concentration of salt $(\mathrm{NaBr})$ arising from cationic-anionic surfactant neutralization (counterion release). Addition of polylelectrolyte increases the free salt concentration in the system and thus screens even further the vesiclevesicle repulsions. It can thus be observed that very low concentrations of polymer charge are sufficient to induce phase separation, in this case leading to the formation of solidlike precipitates.

At the molecular level, the adsorption of the polyelectrolyte on the vesicle surface may induce dramatic structural effects on the vesicles. Extensive work has been done for the case of mixtures of polypeptides or peripheral proteins and charged liposomes, model systems which directly resemble cell environments. ${ }^{17-20}$ Different phenomena arising from local polyel ectrolyteoppositely charged amphiphile interactions in vesicle systems have been reported for some time. The polyel ectrolyte has been seen to induce a rise in the gel-tofluid transition temperature of the lipid chains of the vesicle. ${ }^{47,48}$ The polyelectrolyte can al so induce an asymmetry in composition between the inner and outer layer in mixed charged liposomes (polyel ectrolyte-induced flipflop). ${ }^{49}$ Formation of microdomains in the vesicle surface has been demonstrated by ${ }^{2} \mathrm{H}$ NMR when a polycation adsorbs in mixed anionic-zwitterionic lipid vesicles. ${ }^{22}$

In the polymer-catanionic vesicle systems studied here, it is clear that the macromolecule induces morphological changes in the bilayer already at very low overall charge neutralization. The vesicle shape is no longer spheroidal and faceted vesicles form instead. This morphology of the bilayer is visibly similar to that seen for lipid vesicles in the gel phase, i.e. for vesicle dispersions below their chain transition temperature $\left(T_{c}\right)^{5}{ }^{5}$ The observed facets in the J R400- and LM200vesicle systems seem to be a direct consequence of polymer adsorption onto the vesicle surface. It is also possible that due to the specific interaction between polymer charges and the anionic SDS molecules, the polymer may induce domain formation in the catanionic membrane and/or an increase in the $T_{c}$ for the catanionic vesides. The deformations of the bilayer wall could also result from polymer-mediated vesicle-vesicle attractive forces, since both polymers are able to bridge several vesicles, as discussed below.
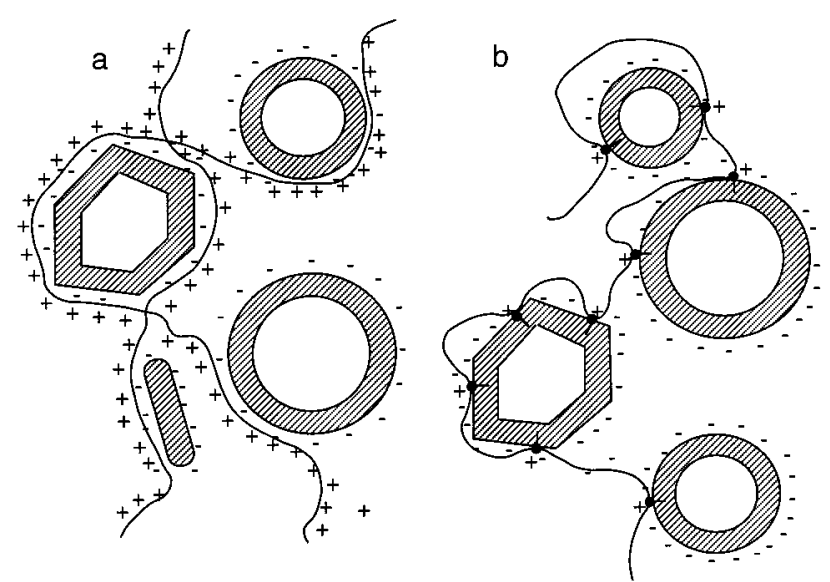

Figure 11. Schematic view of the possible structure for the gel-like samples, involving polymer-aggregate networks. (a) The J R400 system, where mainly electrostatic interactions occur. F aceted and spherical vesicles are depicted, as well as disklike aggregates (shown in edge-on position), in accordance with cryo-TEM imaging. (b) The LM200 system, where both hydrophobic and electrostatic interactions are present. This type of cross-linking could explain the "gel" formation and also the isolated clusters imaged in the surfactant-rich solution phase.

Some qualitative differences exist between the effects induced by J R400 and by LM200 as the polymer concentration is increased toward phase separation. J R400 is a larger molecule $(\approx 1 \mu \mathrm{m})$ than LM 200 , it has higher charge density but bears no grafted chains. It can be reasonably be seen as flexible polymer in a sea of vesicles. Due to its dimensions and the electrostatic interactions, it can bridge several of these aggregates, whose average size is around $30 \mathrm{~nm}$. As the J R400 concentration increases, the closed faceted vesicles are no longer the only stable structure and small disklike aggregates can be seen. In comparison with the homopolymer, LM200 has lower charge density and smaller contour length but the possibility of anchoring directly in the bilayer through its alkyl side chains. In this case the polymer adsorption involves molecular contact between the polymer and the vesicle. The formation of disk aggregates seems to be less favored in this system, for reasons that require further investigation. Two main effects are induced: (i) formation of ruptured, faceted vesicles and (ii) formation of clusters of vesicles, seemingly due to vesicle-vesicle bridging by the polymer chains.

2. Microstructure of the Polymer-Rich Phase. At very high polymer concentration, the occurrence of markedly viscous samples in the J R400- and LM200catanionic systems displaying a bluish appearance suggests the presence of large aggregates. Oscillatory theological measurements indicate a gel-like viscoelastic behavior for these samples, and the existence of the aggregates could be confirmed by the cryo-TEM method. The TEM data show that the structure of the gel may involve different types of surfactant aggregatesvesicles, disks, or large membrane fragments-depending on polymer-surfactant charge stoichiometry. This structural polymorphism might be reflected in the observed trends for the rheological behavior. In Figure 11a a schematic view of the possible structure for the network involving polymer and surfactant aggregates in the J R400 system is presented, on the basis of the cryo-TEM imaging. 
The formation of gels occurs for roughly similar values of the molar fraction of polymer charge in both systems, thus implying that electrostatics is the main driving force for gel formation. For the LM200 system, however, the alkyl chains of the polymer can also anchor hydrophobically to the oppositely charged bilayer. Thus, the gel can be intuitively pictured as a network of vesicles, or other type of bilayered aggregates, cross-linked by the polymer backbone in molecular contact with the bilayer (Figure 11b). We note that vesicle-polymer networks have been previously suggested for some systems containing hydrophobically modified polymers, ${ }^{10,11}$ but to our best knowledge this is the first TEM indication for such type of network structures. The strong hydrophobic interactions can considerably increase the viscosity of the LM 200 gels as compared to the J R400 ones (where only electrostatic interactions play a role), for similar values of charge stoichiometry. Indeed, comparatively stronger gels are observed by the naked eye for the L M200-catanionic system. It is likely that for this system, the ratio between surfactant tails and polymer hydrophobes is also a determining factor on the dynamic properties of the gel. A systematic rheological characterization of this type of gels is being currently undertaken, in close connection with the direct structural imaging.

Acknowledgment. We are grateful to J oão Luís Bel o for technical assistance in the course of this work. E.F.M. acknowledges Praxis XXI (F.C.T., Portugal) for a research grant (ref. BD/9295/96). O.R. acknowledges a grant from the Swedish Institute for his stay in Lund. The Swedish Research Council for Engineering Sciences (TFR) and PRAXIS XXI (project 2/2.1/QUI/411/94) are also kindly acknowledged for other financial support. The Biomicroscopy Unit at the Chemical Center, Lund University is acknowledged for support in the electron microscopy study. The equipment at the Biomicroscopy Unit was financed by the Knut and Alice Wallenberg Foundation.

\section{References and Notes}

(1) Ringsdorf, H.; Schlarb, B.; Venzmer, J . Angew. Chem. Int. Ed. Eng. 1988, 27, 113.

(2) Sackman, E. FEBS Lett. 1994, 346, 3.

(3) Gennes, P. G. d. J . Phys. Chem. 1990, 94, 8407.

(4) Raudino, A.; Castelli, F. Macromolecules 1997, 30, 2495.

(5) Lasic, D. D. Liposomes: from Physics to Applications; Elsevier: Amsterdam, 1993

(6) Kuhl, T.; Guo, Y. Q.; Alderfer, J . L.; Berman, A. D.; Leckband, D.; I sraelachvili, J .; Hui, S. W. Langmuir 1996, 12, 3003.

(7) Van de Pas, J. C.; Buytenhek, C. J . Colloids Surf. 1992, 68, 127.

(8) Caria, A.; Regev, O.; Khan, A. J . Colloid Interface Sci. 1998, 200, 19.

(9) Van de Pas, J . C.; Olsthoorn, T. M.; Schepers, F.J .; De Vries, C. H. E.; Buytenehek, C. J . Colloids Surf. A 1994, 85, 221.

(10) Loyen, K.; Iliopoulos, I.; Audebert, R.; Olsson, U. Langmuir 1995, 11, 1053.

(11) Meier, W.; Hotz, J .; Günther-Ausborn, S. Langmuir 1996, 12, 5028.

(12) Kevelam, J .; Breemen, J . F. L. V.; Blokzijl, W.; Engberts, J . B. F. N. Langmuir 1996, 12, 4709.

(13) Polozova, A. Biochim. Biophys. Acta 1997, 1326, 213.

(14) Everaars, M. D.; Nieuwkerk, A. C.; Denis, S.; Marcelis, A. T. M.; Sudhölter, E. J . R. Langmuir 1996, 12, 4043.
(15) Porcar, I.; Garcia, R.; Gómez, C.; Campos, A.; Abad, C. Polymer 1997, 38, 5107

(16) Yaroslavov, A. A.; Koulkov, V. Y.; Yaroslavova, E. G.; Ignatiev, M. O.; Kabanov, V. A. Langmuir 1998, 14, 5999.

(17) De Kruijff, B.; Rietveld, A. B.; Telders, N.; Vaadranger, A. Biochim. Biophys. Acta 1985, 820, 295.

(18) Kinnunen, P. K. J ; Köiv, A.; Lehtonen, J . Y. A.; Mustonen, P. Chem. Phys. Lipids 1994, 73, 181.

(19) McLaughlin, S.; Aderem, A. Trends Biochem. Sci. 1995, 20, 272.

(20) Yang, L.; Glaser, M. Biochemistry 1995, 34, 1500.

(21) Antonietti, M.; Kaul, A.; Thüneman, A. Langmuir 1995, 11 2633.

(22) Cromwell, K. V.; Macdonald, P. M. J . Phys. Chem. 1998, 102, 9091.

(23) Diederich, A.; Bähr, G.; Winterhalter, M. Langmuir 1998 $14,4597$.

(24) Murphy, A.; Hill, A.; Vincent, B. Ber. Bunsenges. Phys. Chem. 1996, 100, 963.

(25) Marques, E. F.; Regev, O.; Khan, A.; Miguel, M. G.; Lindman, B. J . Phys. Chem. B 1998, 102, 6746.

(26) Regev, O.; Marques, E. F.; Khan, A. Langmuir 1999, 15, 642.

(27) Lindman, B.; Thalberg, K. Polymer-surfactant interactionsrecent developments. In Interactions of surfactants with polymers and proteins; Goddard, E. D., Ananthapadmanabhan, K. P., Eds.; CRC Press: Boca Raton, FL, 1993; pp 203276.

(28) Piculell, L.; Lindman, B.; Karlström, G. Phase behavior of polymer/surfactant systems. In Polymer-Surfactant Systems; Kwak, J. C. T., Ed.: Marcel Dekker: New York, 1998.

(29) Goddard, E. D. Colloids Surf. 1986, 19, 255.

(30) Goddard, E. D. Polymer-Surfactant Interaction. Part II. Polymer and Surfactant of Opposite Charge. In Interactions of Surfactants with Polymers and Proteins; Goddard, E. D., Ananthapadmanabhan, K. P., Eds.; CRC Press: Boca Raton, $\mathrm{FL}$, 1993; pp 171.

(31) Guillemet, F.; Piculell, L. J . Phys. Chem. 1995, 99, 9203.

(32) Goldraich, M.; Schwartz, J . R.; Burns, J. L.; Talmon, Y. Colloids Surf. 1997, 125, 231.

(33) Dhoot, S.; Goddard, E. D.; Harris, E. C.; Murphy, D. S. Colloids Surf. 1992, 66, 91.

(34) Thuresson, K.; Nilsson, S.; Lindman, B. Langmuir 1996, 12 530.

(35) Guillemet, F. Polyeléctrolytes associatifs en présence de tensioactifs: Phénomènes d'épaissement et de séparation de phase. Thèse de Doctorat, Université de Paris VI, 1995.

(36) Bellare, J. R.; Davis, H. T.; Scriven, L. E.; Talmon, Y. J . Electron Microsc. Tech. 1988, 10, 87.

(37) Vinson, P. K. Cryo-TEM, carbon-coated holey polymer film; The 45th Annual Meeting of the Electron Microscopy Society of America, San Francisco, CA, 1987.

(38) Marques, E.; Khan, A.; Miguel, M. G.; Lindman, B. J . Phys. Chem. 1993, 97, 4729.

(39) Goddard, E. D.; Leung, P. S. Colloids Surf. 1992, 65, 211.

(40) Harwigsson, H.; Söderman, O.; Regev, O. Langmuir 1994, 10, 4731.

(41) Süss, D.; Cohen, Y.; Talmon, Y. Polymer 1995, 39, 1809.

(42) Goddard, E. D.; Hannan, R. B. J . Colloid I nterface Sci. 1976, $54,73$.

(43) Goddard, E. D.; Hannan, R. B. J . Am. Oil Chem. Soc. 1977 $54,561$.

(44) Leung, P. S.; Goddard, E. D. Colloids Surf. 1985, 13, 47.

(45) Evans, D. F.; Wennerström, H. TheColloidal Domain: Where Physics, Chemistry, Biology and Technol ogy Mee; VCH: New York, 1994.

(46) Boruhkov, I.; Andelman, D.; Orland, H.J . Phys. Chem. 1999, 103,5042

(47) Hartmann, W.; Galla, H.-J . Biochim. Biophys. Acta 1978, 509, 474.

(48) Laroche, G.; Pezolet, M.; Dufourcq, J .; Dufourcq, E. Prog. Colloid Polym. Sci. 1989, 79, 38.

(49) Kabanov, V. A.; Yaroslavov, A. A.; Sukhishvili, S. A. J. Controlled Release 1996, 39, 173.

MA990350+ 